\title{
A Relevância da Estrutura de Capital no Desempenho das Firmas: uma Análise Multivariada das Empresas Brasileiras de Capital Aberto
}

\section{Resumo}

As mudanças econômicas ocorridas nos últimos anos tornaram a dinâmica do mercado brasileiro mais complexo, o que impacta diretamente na administração de grandes organizações, principalmente em tarefas de cunho gerencial, como é o caso das decisões referentes à definição da estrutura de capital. Contudo, a literatura desse campo teórico está polarizada em dois trabalhos seminais: o primeiro, de Durand $(1952,1959)$, aborda a existência de uma estrutura ótima de capital que maximiza o valor da firma; e, no outro extremo, o trabalho de Modigliani e Miller $(1958,1963)$ considera que o modo como as firmas se financiam é irrelevante. Nesse sentido, o objetivo foi verificar a efetiva interferência da estrutura de capital no desempenho das firmas brasileiras listadas na BM\&FBOVESPA. A amostra se constituiu em dados de corte transversal (cross section) e foram selecionados dos últimos balanços de todas as empresas listadas na BM\&FBOVESPA, disponíveis na base de dados Economática. As técnicas utilizadas foram a análise de variância (ANOVA) e a análise discriminante. Entre os indicadores utilizados, observou-se que apenas a liquidez geral, o grau de imobilização, a Q de Tobin, e a oportunidade de crescimento, foram significativas a $1 \%$. Os resultados encontrados indicam que a estrutura de capital não está diretamente relacionada com o desempenho das firmas brasileiras listadas na BM\&FBOVESPA. Nesse ínterim, os resultados apontam para a consolidação das teorias financeiras expostas por Modigliani e Miller $(1958,1963)$ em oposição à corrente tradicionalista iniciada nos estudos de Durand (1952).

Palavras chave: Estrutura de capital; Teorias financeiras; Desempenho das firmas.
Luiz Kennedy Cruz Machado Mestrando em Administração pela Universidade Federal de Lavras (UFLA). Contato: Departamento de Administração e Economia, Campus Universitário, LavrasMG, CEP: $37200-000$.

E-mail: luizken@yahoo.com.br

José Willer do Prado Mestrando em Administração pela Universidade Federal de Lavras (UFLA). Contato: Departamento de Administração e Economia, Campus Universitário, LavrasMG, CEP: 37200-000.

E-mail: jwprado@gmail.com

\section{Kelly Carvalho Vieira}

Mestre em Administração pela Universidade Federal de Lavras (UFLA) e professora da Universidade Federal de Viçosa (UFV). Contato: Rodovia LMG, km 06, FlorestalMG, CEP: 35690-000.

E-mail: kellycarvalho1108@hotmail.com

Luiz Marcelo Antonialli Doutor em Administração pela Universidade de São Paulo (USP) e professor da Universidade Federal de Lavras. Contato: Departamento de Administração e Economia, Campus Universitário, LavrasMG, CEP: 37200-000.

E-mail: Imantonialli@dae.ufla.br

Antônio Carlos dos Santos Doutor em Administração pela Universidade de São Paulo (USP) e professor da Universidade Federal de Lavras. Contato: Departamento de Administração e Economia, Campus Universitário, LavrasMG, CEP: 37200-000.

E-mail: acsantos@dae.ufla.br 


\section{Introdução}

Nas últimas duas décadas, o mercado brasileiro sofreu bruscas mudanças econômicas devido principalmente a fatores, como a estabilização da moeda, a liberalização cambial e a abertura comercial. Esses fatos proporcionaram a entrada de multinacionais no país e tornaram a dinâmica do mercado brasileiro mais complexa, o que impacta diretamente na administração de grandes organizações, sobretudo em tarefas de cunho gerencial, como é o caso das decisões referentes à estrutura de capital.

Nesse ínterim, para acompanhar a complexidade do mercado, as firmas se veem em constantes necessidades de investimentos tanto em estrutura como em tecnologia, na qual a base de seu financiamento é uma questão passível de análise. Do exposto, pode-se observar que, no mainstream da teoria Financeira, encontram-se estudos sobre a relevância da estrutura de endividamento para o desempenho da firma e sua respectiva criação de valor no mercado. Entretanto, esses estudos apontam certa divergência sobre a estrutura ótima de capital das firmas, mais especificamente na relevância entre o aumento da dívida ou a utilização de capital próprio como instrumentos de financiamento.

A literatura desse campo teórico está polarizada em dois trabalhos seminais, sendo o primeiro de Durand (1952), no qual o autor abordou a existência de uma estrutura ótima de capital, afirmando que o custo de capital de terceiros permanece estável até determinado nível de endividamento e, a partir desse nível, a firma torna-se mais propensa ao risco de falência. No outro extremo, está a corrente teórica baseada no trabalho de Modigliani e Miller (1958) que considera irrelevante o modo como as firmas se financiam. As duas correntes teóricas se dividem no ponto que as decisões de financiamento são relevantes ou são irrelevantes para alterar o valor da empresa.

Myers e Majluf (1984) e Myers (1984) desenvolveram trabalhos que analisaram as duas óticas sobre a estrutura de capital. A primeira delas, nomeada de Static Trade Off (STO), de Myers (1984), utiliza um modelo que tem o intuito de equilibrar o risco de falência proveniente das dívidas e as vantagens fiscais do endividamento. O modelo indica uma relação harmônica entre alavancagem financeira e o desempenho econômico (Andersen, 2005). O segundo modelo, chamado de Pecking Order Theory ( POT) (teoria de Hierarquia das Escolhas), de Myers e Majluf (1984), tenta apontar uma ordem das fontes de captação de recursos das firmas, em que inicialmente, a opção seria de autofinanciamento, seguido pelos títulos negociáveis em seu poder. Por fim, a utilização de fontes externas, que são tidas como seguras (Ferreira \& Brasil, 1997).

Nesse vértice, partindo dos pressupostos divergentes de Durand (1952) e Modigliani e Miller (1958), cabe o seguinte questionamento: A estrutura de capital (endividamento) exerce influência no desempenho (ou no valor de mercado) das firmas de capital aberto no Brasil? Com o intuito de responder esta pergunta, o presente trabalho tem por objetivo verificar a efetiva interferência da estrutura de capital no valor da firma.

Por conseguinte, as hipóteses levantadas no estudo são: $H_{0}$ : A estrutura de capital não está relacionada com o desempenho das firmas brasileiras listadas na BM\&FBOVESPA e $H_{1}$ : A estrutura de capital está relacionada com o desempenho das firmas brasileiras listadas na BM\&FBOVESPA.

O trabalho está estruturado em cinco seções, incluindo-se esta introdução. No próximo tópico, apresentamos o referencial teórico como alicerce a elucidar o modelo teórico de Durand e também o de Modigliani e Miller e outras teorias afins, como a administração financeira dentro das firmas. A seguir, está a metodologia utilizada no trabalho, acompanhada dos resultados e discussão. Por fim, são apresentadas as considerações finais. 


\section{Referencial Teórico}

Existem várias teorias na literatura que abordam a estrutura de capital como tema central (Jensen \& Meckling, 1976; Ross, 1977; Myers, 1984; Myers \& Majluf, 1984; Baker \& Wurgler, 2002; Rajan, 2012), entretanto, nenhuma delas domina o campo teórico e proporciona um consenso entre os pesquisadores da área (Myers 2001; Zou \& Xiao, 2006; Albanez, 2012; Martins \& Famá, 2012; Almeida, 2014; Nisiyama \& Nakamura, 2014; Mangafić \& Martinović, 2015).

Dado o exposto, é possível polarizar essa temática em duas correntes teóricas que tratam a estrutura de capital focada no valor das empresas. Uma proposta por Durand (1952, 1959), referente à teoria Tradicional, que destaca a existência delas é uma estrutura ótima de capital e, em contrapartida, outra corrente teórica desenvolvida a partir de Modigliani e Miller (1958, 1959, 1963), a qual considera que, sob certas condições, o modo como as firmas se financiam é insignificante (Bonacim, Ambrozini, \& Nagano, 2006; Perobelli \& Famá, 2002).

Andersen (2005) assinala que existe uma relação proporcional entre a alavancagem financeira e o desempenho econômico da firma, indo de encontro com os pressupostos de Durand (1952, 1959), e também a Static Tradeoff Theory (STT) proposta por Myers (1984), que objetiva balancear o risco de falência causado pelo grande número de dívidas com os respectivos ganhos fiscais do endividamento.

De outra face, para Modigliani e Miller $(1958,1959,1963)$, não existe uma combinação ótima de endividamento e capital próprio que minimize os custos de financiamento da empresa e, desta forma, maximize seu valor. Eles afirmam que, seguindo algumas premissas de mercado perfeito e livre de impostos, o modo como as empresas se financiam é irrelevante, isto é, uma firma alavancada tem o valor de mercado igual de uma firma não alavancada.

Nesse mesmo contexto, a corrente exposta por Myers e Majluf (1984), denominada de Pecking Order Theory (POT), expõe que os gestores criam uma ordem de preferência para financiar seus projetos internos, primeiro por meio de financiamentos internos, seguido pela criação de novas dívidas; e, por último, com a captação de recursos obtidos com a emissão de novas ações.

\subsection{Modelo Tradicionalista de Durand $(1952,1959)$}

Conforme mencionado anteriormente, Durand (1952, 1959), o principal representante da Escola Tradicionalista, define que há uma combinação ótima de endividamento e capital próprio que maximize o valor da firma. Segundo a teoria Tradicional, a estrutura de capital interfere no valor da empresa, pois o custo do capital de terceiros altera-se conforme o risco apresentado pela empresa, ou seja, o risco aumenta na medida em que a firma se endivida. Todavia, o risco é compensado pelo aumento da taxa cobrada pelo empréstimo de capital de terceiros, sendo viável sua utilização até o ponto que o custo de capital total atinja um patamar mínimo (Angonese, Santos, \& Lavarda, 2011).

Os tradicionalistas utilizam do Custo Médio Ponderado de Capital (CMPC), que é resultado da média ponderada do custo do capital de outrem e do capital próprio da empresa, para se fundamentarem, afirmando que a minimização deste motivaria uma estrutura ótima de capital (Silva Junior, 2012).

Assaf Neto (2009) explana que as empresas competitivas dão maior ênfase às estratégias de financiamento mediante a substituição de capital próprio por capital de terceiros. As taxas de juros inferiores ao retorno da aplicação desses recursos e os benefícios fiscais decorrentes das despesas de juros admitem que ocorra uma alavancagem financeira favorável, aumentando os resultados dos proprietários e valorizando o preço de mercado das ações. 
Nesse contexto, as decisões referentes ao nível de endividamento são decisivas, como tem demonstrado a recente crise financeira global, forçando empresas altamente alavancadas a equilibrar sua Estrutura de Capital por meio da emissão de ações (Brusov, Filatova, Orehova, \& Brusova, 2012; Islam \& Khandaker, 2015).

\subsubsection{Static Tradeoff Theory (STT)}

O crescente estudo das STT e POT, nas últimas décadas, tem-se mostrado como guia das pesquisas no campo de finanças. Minardi e Sanvicente (2009) dizem que tanto a teoria de Trade-off como a Pecking Order possuem intersecção com outras, como a teoria da Agência e Assimetria de Informações. De acordo com Cruz, Mendes, Espejo e Dameda (2008), os estudos relacionados a benefícios tributários da dívida, risco de falência, conflitos de agência e possíveis sinalizadores da existência de uma estrutura ótima de capital têm sido associados a Trade-off.

A visão que diverge da preposição de Modigliani e Miller segundo Damodaran (2004), é que a STT pode funcionar sobre a dívida a favor da empresa. A estrutura ótima de capital é obtida do fato de que o endividamento proporciona ganhos até um determinado valor e, a partir dele, o resultado inverteria ( $\mathrm{Si}$ rihal \& Melo, 1999). Os mesmos autores desenvolveram um esquema que resume os ganhos e perdas referentes ao endividamento disposto na literatura. Segue uma síntese do modelo:

Vantagens do endividamento: 1) benefício fiscal com a dedução das despesas de juros, sendo que, quanto maior os impostos, maior o benefício; 2) disciplina obtida na separação entre gerentes e acionistas gera ganhos no endividamento.

Desvantagens do endividamento: 1) quanto maior o endividamento maior o fluxo de juros a pagar e maior o custo das dívidas (custo de falência); 2) custo de agência devido aos custos de monitoramento e custos de oportunidade devido às cláusulas restritivas.

Damodaran (2004) ressalta que a exposição da empresa à inadimplência oriunda das suas operações pode não ser o bastante para honrar com suas obrigações. Os custos referentes às dívidas estão intimamente relacionados à possibilidade de destruição da firma.

Adiante, alguns dos trabalhos recentes que utilizam a Static Tradeoff Theory (STT) podem destacar os estudos de Casey (2012), Correa, Cruz Basso e Nakamura (2013), Hovakimian, Kayhan e Titman (2012), Ghazouani (2013), Canarella, Nourayi e Sullivan (2014) e Serrasqueiro e Caetano (2015).

\subsection{Modelo de Modigliani e Miller - MM (1958, 1963)}

O trabalho de Modigliani e Miller (1958) veio contestar a teoria Tradicional, que relacionava o valor da firma com sua estrutura de capital. As hipóteses de Modigliani e Miller da teoria Moderna defendem que o valor da firma é livre do modo como os ativos são financiados, estando relacionado unicamente com o retorno esperado dos projetos da firma. Em 1963, Modigliani e Miller inseriram os encargos financeiros como custo fiscal na resolução das proposições expostas por eles em 1958. Relataram que o valor da empresa deve ser definido pelo valor líquido atual de todos os seus investimentos, acrescido pelo valor dos benefícios fiscais do endividamento.

As proposições de Modigliani e Miller (1958) dizem respeito à valoração de títulos com diferentes estruturas de capitais. Porém, vale ressaltar que as proposições estão sujeitas a três premissas básicas; as taxas de financiamento para pessoas jurídicas são iguais às taxas de financiamento de pessoas físicas; os mercados são eficientes e admitem que o equilíbrio seja sempre restaurado ligeiramente; e não há impostos sobre os ganhos de capital. 
As três proposições do modelo de Modigliani e Miller (1958) são:

I ) O valor de mercado de uma firma qualquer é independente de sua estrutura de capital e é dado pela capitalização dos seus retornos esperados a uma taxa constante apropriada para sua classe de risco, assim como seu Custo Médio de Capital (CMC) é igual ao de uma empresa sem dívidas.

II) O retorno esperado do capital próprio é idêntico ao retorno esperado de uma firma sem dívidas, mais um prêmio de risco proporcional ao nível de endividamento.

III) Apenas apresenta que a política de investimentos da empresa independe do tipo de financiamento usado, sendo uma consequência da proposição anterior. O importante para avaliação do investimento é averiguar se a rentabilidade é maior que a taxa de capitalização da firma em sua classe determinada.

No trabalho de Modigliani e Miller publicado em 1963, os autores fizeram uma correção das proposições feitas do artigo de 1958, afirmando que a estrutura de capital não afeta o valor da empresa. Mas esse valor pode sofrer influências das imperfeições do mercado, tais como o imposto de renda. Silva (2013) diz que Modigliani e Miller verificaram que, apesar do efeito fiscal que os juros do endividamento propiciam à firma, não deverá endividar-se totalmente, sob pena de perder sua tolerância à gestão da tesouraria e da opção de escolha de suas fontes de financiamento. Em síntese, não se pode afirmar que a estrutura de capital é irrelevante quando se calcula o benefício fiscal do endividamento.

\subsubsection{Pecking Order Theory (POT)}

As suposições da POT estão relacionadas com as problemáticas da assimetria informacional, apoiando para uma ausência de estrutura de capital ótima (Cruz et al., 2008). Alguns estudiosos consideram o trabalho de Donaldson (1961) como o marco dos estudos sobre as origens das fontes de financiamento, mas foi apenas em 1984 que Myers o aplicou na área de finanças. Segundo Ferreira e Brasil (1997), a POT, também conhecida como teoria da Hierarquização das Fontes de Financiamento, objetiva explicar uma ordem nas fontes de captação de recursos utilizadas pelas firmas.

Conforme sustenta Myers (1984), não existe uma meta para o endividamento, pois ele acontecerá à medida que surgem as oportunidades de investimento. A POT não define um nível (meta) de endividamento ideal, pois ele ocorrerá com o surgimento de oportunidade de investimento. Outra hipótese que a POT sustenta e que contesta a STT, é que as empresas tentam emitir seus títulos quando estes estão elevados, no qual se emitem mais dívidas e, não, capital próprio, com o intuito de conciliar a estrutura de capital da empresa.

Novamente em 1984, Myers desenvolveu um trabalho junto com Majluf, no qual analisaram os efeitos da assimetria informacional entre os gerentes internos, com seu maior conhecimento sobre as oportunidades de investimentos do que os credores e financeiros externos. Os autores partem do pressuposto de que a obtenção de recursos corresponde a uma ordem de importância: financiamento interno; distribuição de dividendos, considerando as oportunidades de investimento; utilização prioritária de títulos mais seguros; emissão de dívida acompanhada da emissão de títulos conversíveis; e, por fim, recorrência à participação acionária externa (Cruz et. al., 2008).

Em virtude do que foi mencionado, Myers e Mujluf (1984) afirmam que o financiamento por meio de recursos internos, ou de dívida com risco próximo de zero, não alerta o mercado sobre suas estratégias e não altera o valor da ação de uma empresa. Em contrapartida, a emissão de novas ações reduzirá o preço das existentes. Neste contexto, entre os estudos mais recentes, utilizando Pecking Order Theory (POT), podem-se destacar os trabalhos de Atiyet (2012), Mukherjee e Mahakud (2012), Abhijit (2013), Chen, Chen, Chen e Huang (2013), Pirtea, Nicolescu e Boţoc (2014) e Bartholdy, Mateus e Olson (2015). 


\subsection{Administração Financeira dentro das Firmas}

A análise financeira permite um diagnóstico da empresa com sua principal finalidade, que é determinar quais são os pontos críticos da gestão, e possibilita a apresentação de um esboço das prioridades para a solução de seus problemas (Matarazzo, 2007). Padoveze (2003) ainda destaca que a análise financeira é um recurso mínimo necessário para a avaliação contínua das questões de relacionamentos de uma organização, sendo que o foco da gestão econômica deve ser a construção de modelos que possibilitem a sua maximização.

As análises financeiras e suas inúmeras ferramentas possibilitam a formação de diferentes estruturas de capital, que, segundo Ross, Westerfield e Jaffe (2007), podem utilizar muito ou pouco capital de terceiros, emitir variados tipos de ações, recorrer a empréstimos, financiamentos, títulos de dívida, entre outros. As teorias de estrutura de capital são direcionadas para a importância da decisão de financiamento das firmas, com pouca relação à hipótese da eficiência dos mercados e, destaca-se o efeito de possíveis imperfeições sobre a escolha da estrutura ótima de capital, particularmente a presença de assimetria de informação (Bressan, Bressan, Lima, \& Braga, 2008).

\subsubsection{Estrutura de capital}

A estrutura de capital é a forma como a empresa compõe seu financiamento, sendo proveniente do capital próprio ou capital de terceiros, em um período de curto e/ou longo prazo. Independente da origem do financiamento espera-se um retorno positivo apenas pelo fato da aplicação despendida (Cruz et. al., 2008).

Por meio do cálculo da razão entre os recursos de terceiros permanentes e os recursos próprios (patrimônio líquido), obtêm-se a alavancagem financeira da empresa. Quando maior a proporção de capital de terceiros na composição da estrutura de capital, mais alavancada a empresa está, ou seja, maior será seu índice de endividamento (Groppelli \& Nikbakht, 2002).

Conforme enfatizam Bressan et al. (2008), a STT defende que as firmas constituem uma meta ótima de endividamento, e, por outro lado, a POT argumenta que as decisões de financiamento incidem de acordo com uma ordem de preferências, conforme dito anteriormente.

A formação da estrutura de capital não se limita apenas a ter, ou não, capital de terceiros financiando os investimentos da firma; o processo é mais complexo; e existem outros quesitos que devem ser considerados, como o prazo de pagamento da dívida, as características do endividamento e dos contratos, os custos de transação envolvidos no processo e a assimetria informacional. Tal fato corrobora que esse campo teórico está longe de esgotar suas pesquisas e obter um consenso entre os pesquisadores.

\section{Metodologia}

O presente estudo dar-se-á por meio de uma pesquisa exploratória de natureza quantitativa (Hair, Black, Babin, Anderson, \& Tatham, 2009). O banco de dados foi selecionado em corte-transversal (cross section), contendo os últimos balanços disponíveis no exercício (valor final) para o ano de 2014, de todas as empresas consolidadas disponíveis na base de dados da Economática, seguindo as normas brasileiras do IFRS (que são as Normas e Padrões Internacionais de Contabilidade, do termo em inglês International Financial Reporting Standards). Os dados foram tabulados e analisados mediante a utilização do software Statistic Package for the Social Science (SPSS).

Após a eliminação das empresas que possuíam dados faltantes, a amostra se constituiu de $238 \mathrm{em}$ presas de diversos setores e os que mais se destacam são o setor de energia elétrica, com 35 empresas, e o de construção, com 21 firmas. 
As variáveis utilizadas foram definidas com base em diversos estudos empíricos já realizados neste campo, entre esses destaca-se: Titman e Wessels (1988), Oliveira e Antonialli (2004), Bezerra e Corrar (2006), Bonacim et al. (2006), Ross et al. (2007), Bressan et al. (2008) e Grzebieluckas, Marcon, Alberton e Mello (2008). Como vários índices são recorrentes nos trabalhos, buscou-se um escopo que fosse representativo para a devida temática.

As variáveis selecionadas para pertencer à presente amostra foram divididas em três categorias, sendo a primeira as variáveis de endividamento da firma, seguida pelas variáveis de desempenho da firma e por último as variáveis de controle. Essas podem ser mais bem visualizadas no Tabela 1.

Tabela 1

\section{Indicadores utilizados como variáveis independentes}

\begin{tabular}{|c|c|c|}
\hline Descrição & Siglas & Índices/Medidas \\
\hline \multirow{3}{*}{$\begin{array}{l}\text { Endividamento } \\
\text { da Firma }\end{array}$} & Endividamento total & $\frac{\text { Dívidas Totais }}{\text { Ativo Total }}$ \\
\hline & Endividamento de longo prazo & $\frac{\text { Passivo Não Circulante }}{\text { Ativo Total }}$ \\
\hline & Endividamento de curto prazo & $\frac{\text { Passivo Circulante }}{\text { Ativo Total }}$ \\
\hline \multirow{8}{*}{$\begin{array}{l}\text { Desempenho } \\
\text { da Firma }\end{array}$} & Valor de mercado (VM) & $\begin{array}{c}\text { (Cotação não Ajustada por Proventos * Total de Ações } \\
\text { calculado [exceto tesouraria]) + DTL + Participações Acionistas } \\
\text { Minoritários }\end{array}$ \\
\hline & Q de Tobin & $\frac{\text { Valor de Mercado }}{\text { Ativo Total }}$ \\
\hline & (EVA) & LL - (PL x CDI) \\
\hline & $\begin{array}{l}\text { Retorno sobre Ativo } \\
\text { (ROA) }\end{array}$ & $\frac{\text { Lucro Operacional }}{\text { Ativo Total-Lucro Líquido }}$ \\
\hline & Retorno sobre Patrimônio (ROE) & $\frac{\text { Lucro Líquido }}{\text { Patrimônio Líquido -Lucro Líquido }}$ \\
\hline & Margem Líquida MrgLiq & $\frac{\text { Lucro Líquido }}{\text { Receita de Intermecdiação Financeira }}$ \\
\hline & Liquidez Corrente LC & $\frac{\text { Ativo Circulante }}{\text { Passivo Circulante }}$ \\
\hline & Liquidez Geral LG & $\frac{\text { Ativo Circulante + Realizável a Longo Prazo }}{\text { Passivo Circulante + Exigível a Longo Prazo }}$ \\
\hline \multirow{5}{*}{$\begin{array}{l}\text { Variáveis } \\
\text { de Controle }\end{array}$} & Dimensão da Empresa (Tamanho) & (Log do Ativo total) \\
\hline & Deduções Fiscais & LAJIR - LL \\
\hline & Grau de imobilização (GIM): & $\frac{\text { Ativo Permanente }}{\text { Ativo Total }}$ \\
\hline & Agrupamento genérico da indústria & Classificação Economática ${ }^{\circledR}$ \\
\hline & Oportunidades de crescimento & $\frac{\text { Ativo Total - Patrimôn io Líquido + Valor de Mercado }}{\text { Ativo Total }}$ \\
\hline
\end{tabular}

Legenda: LL = Lucro Líquido; PL = Patrimônio Líquido; DTL = DívidaTotal Líquida; CDI = Certificado de Depósito Interbancário.

Fonte: dados da pesquisa.

No que diz respeito às variáveis de estrutura de capital, a princípio foram utilizadas três métricas (variáveis dependentes), que irão abranger o endividamento contábil total de curto prazo e de longo prazo. O endividamento total representa a participação dos capitais de terceiros no financiamento das atividades da empresa e é equivalente ao conceito de alavancagem (leverage), normalmente empregado nas pesqui- 
sas empíricas na área de finanças (Forte, 2007; Bastos \& Nakamura, 2009; Pohlmann, Aguiar, Bertolucci, \& Martins, 2004; Albanez, 2012).

Dentre as variáveis de desempenho da firma, podem-se destacar o ROE, que segundo Assaf Neto (2009), tem por finalidade avaliar o retorno que a empresa está proporcionando em relação ao capital investido nela pelos seus acionistas; e o ROA (eficiência operacional), que pode ser relacionado com a POT, como salienta Bonacim et al. (2006). Empresas mais lucrativas preferem utilizar recursos próprios oriundos dos lucros em vez de recursos de terceiros, que provocam juros (impacto financeiro).

Nesse sentido, empresas com maiores ROAs apresentarão menores índices de alavancagem, enquanto empresas com menores ROAs serão mais alavancadas. Caso exista igualdade entre os ROAs das empresas com alto grau de alavancagem e com baixo grau de alavancagem, o pressuposto anterior não se confirmará.

Para cálculo do EVA, além das contas coletadas no software Economática, optou-se por utilizar como taxa livre de riscos o Certificado de Depósito Interbancário (CDI) como base de cálculo Pessanha, Calegario, Safadi \& Azara (2012). O CDI utilizado foi divulgado pelo Banco Central do Brasil por meio de boletim financeiro, e foi calculado com a média dos valores referentes ao mês de novembro de 2014 .

Futema, Basso e Kayo (2009) salientam que, na literatura financeira, o valor de mercado é frequentemente considerado como uma aproximação do $\mathrm{Q}$ de Tobin, por incluirem-se as oportunidades de crescimento e a lucratividade corrente, e um índice utilizado pelos analistas de mercado, sendo $\mathrm{q}<1$, o ativo vale menos do que seu custo de reposição, e caso $\mathrm{q}>1$, o ativo vale mais do que seu custo de reposição. $\mathrm{O}$ valor de mercado utilizado foi o último disponível no banco de dados Economática , no dia da coleta dos dados (14/11/2014).

A margem líquida calculada para todas as empresas da amostra é utilizada para obter conhecimentos acerca do retorno de uma determinada empresa. Ela deduz os custos e despesas operacionais, além das despesas financeiras e não operacionais. Braga, Nossa e Marques (2004) citam que a margem líquida mede a porcentagem do lucrou ou prejuízo final em relação às receitas líquidas de vendas.

A Liquidez Geral, segundo Silva (2013), permite medir qual capacidade a empresa possui para fazer face às suas responsabilidades de curto prazo, sendo, desta forma, visto como um teste de solvabilidade de curto prazo para a empresa. Sendo assim, quanto maior for a liquidez geral de uma empresa, maior sua solvabilidade de curto prazo, e caso contrário, quanto menor for a liquidez de curto prazo, mais vulnerável esta se encontra.

De forma geral, o desempenho (lucratividade) da firma, segundo Bressan et al. (2008) e Rajan e Zingales (1995), é negativamente correlacionado com a alavancagem. Entretanto, Daher (2004) considera que quanto maior a lucratividade das empresas, maior será o incentivo ao endividamento, devido à dedutibilidade dos juros do lucro tributável. Colaborando com a discussão, Terra (2002) explana que na trade-offespera-se relação positiva entre lucratividade e alavancagem, enquanto na pecking order espera-se o efeito oposto.

Por fim, são discutidas as variáveis de controle utilizadas, no qual Gomes (1999) e Terra (2002) consideram que a oportunidade de crescimento, quando negativamente correlacionada com o endividamento, colabora com a STT. Entretanto, quando positivamente correlacionada, auxiliam a POT. Segundo os autores, ao contrário da teoria do STT, a POT sugere também que as oportunidades de crescimento estariam positivamente relacionadas com o endividamento da firma. Isso porque firmas com crescimento elevado não disporiam de recursos suficientes para se financiarem com recursos próprios, optando por uma alavancagem maior.

Como variável de controle, também temos o Grau de Imobilização (GIM), que segundo Silva (2013), em empresas com um grande número de ativos não correntes (permanentes), caso ocorra um processo de falência ou liquidação, essas terão mais garantias, pois os credores poderão recuperar o seu dinheiro com a venda destes. Logo, pode-se concluir que empresas com um elevado valor de ativos deste tipo podem ter mais dívida na sua estrutura de capital.

Silva (2013) considera que a dimensão (tamanho) da empresa está indicada na teoria do STT como determinante da estrutura de capital, pois quanto maior for a dimensão da empresa, mais acesso ela tem ao credito e ao mercado de capitais com custos inferiores, permitindo assim reduzir os custos de falência. Para a POT, as empresas de maior dimensão têm mais informação, o que permite uma menor relação com problemas inerentes à assimetria de informação. 
Ademais, as deduções fiscais segundo Silva (2013), enquanto correlacionadas com o endividamento, auxiliam a comprovar a existência da STT. No que diz respeito às deduções fiscais, é possível encontrar um nível de endividamento para cada empresa, sabendo-se que as possuintes de maiores deduções fiscais recorrem mais ao capital alheio do que as outras. Para Titman e Wessels (1988), as deduções fiscais das amortizações e os créditos fiscais para o investimento são substituídos pelos benefícios fiscais obtidos com o financiamento em capitais alheios.

Perobelli e Famá (2002) observam uma polarização extrema para acomodar algumas peculiaridades. Na STT, as empresas trabalham em um cenário onde há isenção de impostos sobre os juros pagos. Elas se financiam unicamente com recursos de terceiros de modo a aproveitar ao máximo os benefícios fiscais do endividamento. Por outro lado, a POT considera que não havendo impostos ou isenção fiscal, a dívida deixa de ser um instrumento atrativo.

Dando prosseguimento, para a análise dos dados, foram utilizadas as técnicas de variância (ANOVA), que é uma técnica de dependência, e a análise discriminante. Segundo Hair et al. (2009), a análise discriminante pode ser vista como uma técnica estatística apropriada, quando se tem uma variável dependente e categórica (nominal ou não métrica) e as variáveis independentes, por sua vez, são métricas.

Virgillito e Famá (2008) afirmam que, existem dois grupos de empresas com duas medidas, V1 e V2, sendo essas suas observações as elipses A e B (desenhadas com pontos pequenos e pontos grandes na Figura 1), seus universos, e Z, o eixo determinado pela sua função discriminante, que, por sua vez, é constituída por índices. Se traçar uma linha reta através da área de interseção das duas elipses e projetar esta linha num novo eixo Z, segundo Hair et al. (2009), pode-se dizer que a área de sobreposição entre as duas distribuições univariadas A e B (representada pela área sombreada na Figura 1), será a menor entre todas as outras retas possíveis de serem traçadas através da área de sobreposição das duas elipses.

A área de sobreposição na Figura 1, que está projetada sobre o eixo Z, pode ser interpretada como a discriminação entre os dois grupos. Sendo assim, quanto menor for a área de sobreposição, menor será o número de empresas com baixo grau de endividamento, classificadas como empresas com alto grau de endividamento e vice-versa.

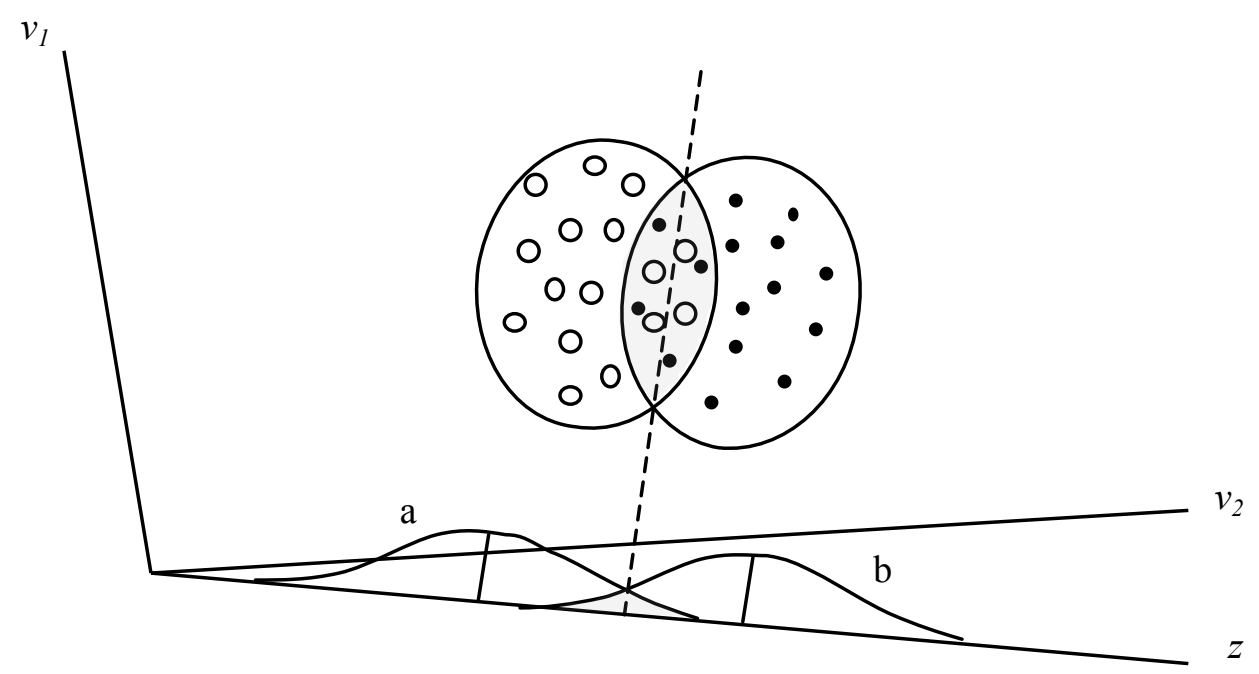

Figura 1. Representação gráfica da análise discriminante de dois grupos

Fonte: Hair et al. (2009, p. 214).

Hair et al. (2009) observa que, a partir da função discriminante (ou função de classificação), obtém-se um escore $Z$ discriminante que representa o resultado composto da multiplicação de cada variável independente por seu peso correspondente. A discriminação dos grupos se dá por meio do estabelecimento dos pesos da variável estatística (variável predita não métrica) para cada variável preditora, no intuito de maximizar a variância entre os grupos e dentro de cada grupo. 
Considera-se que a função discriminante identifica eficientemente os grupos, se a sobreposição das distribuições dos escores discriminantes para os grupos for pequena (Hair et al., 2009).

\section{Resultado e Discussão}

Buscando entender como as variáveis se comportam frente aos níveis de endividamento total, de longo prazo e de curto prazo, foram geradas, a partir do logaritmo das variáveis a correlação entre os três tipos de endividamento adotados e as variáveis da pesquisa. Neste procedimento, pode-se observar, na Tabela 2, que a maioria das variáveis apresentam correlação negativa com os três níveis de endividamento.

A correlação aponta que, quando o endividamento aumenta, quase todas as variáveis tendem a diminuir. Entretanto, observa-se que as relações, estatisticamente, não são todas significativas a 1\% e a 5\%.

Tabela 2

Correlação entre todas as variáveis e os Endividamentos total, longo e curto prazo

\begin{tabular}{|c|c|c|c|c|}
\hline \multicolumn{2}{|c|}{ Correlações - N: 238} & \multirow{2}{*}{$\begin{array}{c}\text { Endiv.T } \\
-0,009\end{array}$} & \multirow{2}{*}{$\begin{array}{c}\text { Endiv. LP } \\
0,110 \\
\end{array}$} & \multirow{2}{*}{$\begin{array}{c}\text { Endiv. CP } \\
-0,189 * \star \\
\end{array}$} \\
\hline VM & Correlação de Pearson & & & \\
\hline VIVI & Sig. (2 extremidades) & 0,885 & 0,090 & 0,003 \\
\hline \multirow{2}{*}{ QdT } & Correlação de Pearson & $-0,317 * *$ & $-0,302 * *$ & $-0,097$ \\
\hline & Sig. (2 extremidades) & 0,000 & 0,000 & 0,135 \\
\hline \multirow{2}{*}{ EVA \% } & Correlação de Pearson & $-0,132^{\star}$ & $-0,118$ & $-0,105$ \\
\hline & Sig. (2 extremidades) & 0,042 & 0,069 & 0,106 \\
\hline \multirow{2}{*}{$\mathrm{ROA}$} & Correlação de Pearson & $-0,168^{* *}$ & $-0,162^{*}$ & $-0,111$ \\
\hline & Sig. (2 extremidades) & 0,009 & 0,012 & 0,088 \\
\hline \multirow{2}{*}{ ROE } & Correlação de Pearson & $-0,161^{*}$ & $-0,140 *$ & $-0,140 *$ \\
\hline & Sig. (2 extremidades) & 0,013 & 0,031 & 0,030 \\
\hline \multirow{2}{*}{ Mrg Liq } & Correlação de Pearson & $-0,225^{* *}$ & $-0,184^{* *}$ & $0,168^{* *}$ \\
\hline & Sig. (2 extremidades) & 0,000 & 0,004 & 0,009 \\
\hline \multirow{2}{*}{ LC } & Correlação de Pearson & $-0,523$ ** &,$- 249 * *$ & $-0,314^{* *}$ \\
\hline & Sig. (2 extremidades) & 0,000 & 0,000 & 0,000 \\
\hline \multirow{2}{*}{ LG } & Correlação de Pearson & $-0,570 * \star$ & $-0,558^{\star *}$ & $-0,053$ \\
\hline & Sig. (2 extremidades) & 0,000 & 0,000 & 0,415 \\
\hline \multirow{2}{*}{ LN. Ativo } & Correlação de Pearson & $0,195^{* *}$ & $0,325^{* *}$ & $-0,158^{*}$ \\
\hline & Sig. (2 extremidades) & 0,003 & 0,000 & 0,014 \\
\hline \multirow{2}{*}{ Ded. Fiscais } & Correlação de Pearson & $-0,009$ & $-0,002$ & $-0,025$ \\
\hline & Sig. (2 extremidades) & 0,892 & 0,974 & 0,698 \\
\hline \multirow{2}{*}{ GIM } & Correlação de Pearson & $-0,029$ & $0,413^{* *}$ & $-0,418^{* *}$ \\
\hline & Sig. (2 extremidades) & 0,659 & 0,000 & 0,000 \\
\hline \multirow{2}{*}{ Oport. Cresc. } & Correlação de Pearson & 0,091 & $-0,105$ & $0,174 * \star$ \\
\hline & Sig. (2 extremidades) & 0,162 & 0,105 & 0,007 \\
\hline
\end{tabular}

**significativa no nível de 0,01; *significativa no nível de 0,05.

Fonte: dados da pesquisa.

Para averiguar o efeito do endividamento sobre as empresas, foram criados dois grupos a partir do índice de Endividamento Total. Para especificação de cada grupo, optou-se por definir como Grupo 1 empresas que exibissem níveis de endividamento menores do que 50\%; e como Grupo 2 empresas que expusessem níveis de endividamento maiores ou iguais a 50\%. A razão para se definir esse ponto de corte parte de uma tentativa de se dicotomizar empresas com alto nível de endividamento de empresas com baixo nível de endividamento, possibilitando, assim, verificar se essas empresas apresentam parâmetros distintos. 
A partir desse processo, do total de 238 empresas pertencentes à amostra, 86 foram classificadas como pertencentes ao Grupo 1, como tendo endividamento inferior a 50\%, e 152 empresas ficaram no Grupo 2, com níveis de endividamento superior a 50\%.

Dando início às análises, utilizou-se a técnica de ANOVA - com dois grupos. O foco da análise de variância é confrontar as médias das populações distintas (Grupo 1 e Grupo 2). Essa comparação busca encontrar diferenças significativas nas variâncias de cada grupo, examinando se esses são parecidos, ou não, e se há influência de alguma variável nos grupos. Como pode ser visto na Tabela 3 , as variáveis $\mathrm{Q}$ de Tobin, EVA \%, ROA, ROE, Mrg Liq, LiqCor, LiqGer e LN do Ativo apresentaram significância estatística de 5\%. Adiante, pode-se constatar essa diferença pelas médias desiguais entre as variáveis, o que confirma a existência de diferença entre empresa com alto grau de endividamento e empresas com baixo grau de endividamento.

Tabela 3

ANOVA a partir do Grupo 1 e do Grupo 2

\begin{tabular}{|c|c|c|c|c|c|c|c|}
\hline \multirow{2}{*}{ ANOVA } & & \multicolumn{4}{|c|}{ Descritivos } & \multirow{2}{*}{$\mathbf{F}$} & \multirow{2}{*}{ Sig. } \\
\hline & & $\mathrm{N}$ & Média & Desvio padrão & Erro padrão & & \\
\hline \multirow{3}{*}{ Valor Mercado } & 1 & 86 & $9,07 E+09$ & $3,05 E+10$ & $3,29 E+09$ & 1,114 & 0,292 \\
\hline & 2 & 152 & $5,92 E+09$ & $1,56 \mathrm{E}+10$ & $1,27 E+09$ & & \\
\hline & Total & 238 & $7,06 \mathrm{E}+09$ & $2,22 E+10$ & $1,44 \mathrm{E}+09$ & & \\
\hline \multirow{3}{*}{ Q de Tobin } & 1 & 86 & 1,020874 & 0,9090582 & 0,0980263 & 16,711 & 0,000 \\
\hline & 2 & 152 & 0,569403 & 0,7627837 & 0,0618699 & & \\
\hline & Total & 238 & 0,732540 & 0,8451788 & 0,0547848 & & \\
\hline \multirow{3}{*}{ EVA \% } & 1 & 86 & 5,541112 & 8,4613126 & 0,9124068 & 3,875 & 0,050 \\
\hline & 2 & 152 & $-4,392998$ & 46,3246803 & 3,7574277 & & \\
\hline & Total & 238 & $-0,803362$ & 37,6273168 & 2,4390167 & & \\
\hline \multirow{3}{*}{$\mathrm{ROA}$} & 1 & 86 & 5,367894 & 8,7581449 & 0,9444151 & 11,880 & 0,001 \\
\hline & 2 & 152 & 1,470146 & 8,1605157 & 0,6619052 & & \\
\hline & Total & 238 & 2,878576 & 8,5708921 & 0,5555684 & & \\
\hline \multirow{3}{*}{ ROE } & 1 & 86 & 8,146424 & 13,2371709 & 1,4274008 & 4,026 & 0,046 \\
\hline & 2 & 152 & $-3,997019$ & 55,1882491 & 4,4763581 & & \\
\hline & Total & 238 & 0,390948 & 45,1392791 & 2,9259449 & & \\
\hline \multirow{3}{*}{ Mrg Liq } & 1 & 86 & 359,273139 & 2285,0030412 & 246,3982147 & 4,075 & 0,045 \\
\hline & 2 & 152 & $-18,845945$ & 269,3723410 & 21,8489820 & & \\
\hline & Total & 238 & 117,785320 & 1397,1261124 & 90,5622348 & & \\
\hline \multirow{3}{*}{ LC } & 1 & 86 & 3,193959 & 4,8039941 & 0,5180280 & 17,515 & 0,000 \\
\hline & 2 & 152 & 1,526602 & 0,7963994 & 0,0645965 & & \\
\hline & Total & 238 & 2,129092 & 3,0537566 & 0,1979456 & & \\
\hline \multirow{3}{*}{ LG } & 1 & 86 & 1,789446 & 1,4670286 & 0,1581938 & 54,142 & 0,000 \\
\hline & 2 & 152 & 0,864854 & 0,3793528 & 0,0307696 & & \\
\hline & Total & 238 & 1,198950 & 1,0303784 & 0,0667895 & & \\
\hline \multirow{3}{*}{ LN do Ativo } & 1 & 86 & 21,494197 & 1,7806333 & 0,1920106 & 5,151 & 0,024 \\
\hline & 2 & 152 & 22,002137 & 1,5858821 & 0,1286320 & & \\
\hline & Total & 238 & 21,818595 & 1,6731242 & 0,1084525 & & \\
\hline \multirow{3}{*}{$\begin{array}{l}\text { Deduções } \\
\text { Fiscais }\end{array}$} & 1 & 86 & $1,04 \mathrm{E}+08$ & $4,41 \mathrm{E}+08$ & $4,76 \mathrm{E}+07$ & 0,004 & 0,948 \\
\hline & 2 & 152 & $1,08 \mathrm{E}+08$ & $4,09 E+08$ & $3,32 E+07$ & & \\
\hline & Total & 238 & $1,06 \mathrm{E}+08$ & $4,20 E+08$ & $2,72 E+07$ & & \\
\hline \multirow{3}{*}{ GIM } & 1 & 86 & 62,535400 & 20,6808571 & 2,2300742 & 1,643 & 0,201 \\
\hline & 2 & 152 & 58,905667 & 21,1571864 & 1,7160744 & & \\
\hline & Total & 238 & 60,217251 & 21,0153200 & 1,3622209 & & \\
\hline \multirow{3}{*}{$\begin{array}{l}\text { Oportunidades } \\
\text { de Crescimento }\end{array}$} & 1 & 86 & 1,381842 & 0,8907297 & 0,0960499 & 1,081 & 0,299 \\
\hline & 2 & 152 & 1,268426 & 0,7579353 & 0,0614767 & & \\
\hline & Total & 238 & 1,309408 & 0,8084204 & 0,0524021 & & \\
\hline
\end{tabular}

Fonte: dados da pesquisa. 
Como pode ser observado, a diferença de média dos grupos é acentuada para variáveis como ROA, que apresentam para empresas com baixo grau de alavancagem um ROA médio de 5,36; já para empresas com alto grau de alavancagem, apresentam um ROA com média de 1,47.

Constatou-se que, para todas as variáveis de desempenho da firma que apresentaram significância estatística, as empresas do Grupo 1 que possuem menores níveis de endividamento demonstram melhor desempenho do que as empresas do Grupo 2, que possuem maiores níveis de endividamento.

Sendo assim, a técnica ANOVA sinaliza para o aporte teórico fornecido pela POT. Como Terra (2002) explana, na STT espera-se relação positiva entre lucratividade e alavancagem, enquanto na POT espera-se o efeito oposto, como o encontrado na análise de variância.

Em momento posterior, optou-se por utilizar da análise discriminante, na tentativa de elucidar quais variáveis mais discriminam os dois grupos propostos. Para essa análise, foi utilizado o método "passo a passo" (stepwise) como seletor das variáveis mais significativas para discriminar entre os grupos $1 \mathrm{e}$ 2. Como menciona Corrar, Paulo, Dias Filho (2007), uma forma para se testar a função discriminante é por meio da divisão da amostra total em duas subamostras: uma para desenvolver a função discriminante (amostra original) e outra para testar a função encontrada (amostra para teste). Neste sentido, a amostra original contou com 187 casos, e a amostra de teste, com 75 casos.

Entretanto, ao analisar a matriz de correlação das variáveis independentes do primeiro modelo gerado com as variáveis originais, constatou-se a existência de uma correlação bem mais acentuada do que as outras $(0,98)$, sendo essa entre o Q de Tobin e a variável oportunidade de crescimento, em que, conforme afirmado por Futema et al. (2009), o Q de Tobin inclui as oportunidades de crescimento da firma. Tal fato acarretou um caso de multicolinearidade (variáveis independentes que possuem relações lineares exatas ou aproximadamente exatas e que, dessa forma, podem até impossibilitar qualquer estimação) confirmado pelo critério de Tolerance.

Field (2009) observa que não existem consequências estatísticas na transformação dos dados, sendo que a transformação pode corrigir valores atípicos, como o caso exposto. Nesse sentido, para evitar a ocorrência de estimadores enviesados e não representativos, optou-se por trabalhar com as variáveis logaritmizadas, podendo-se observar, na Tabela 4, uma alta correlação entre o Q de Tobin e a variável oportunidade de crescimento, de 0,84, e entre o Log do Ativo e o valor de mercado, de 0,86.

Tabela 4

\section{Matriz de correlação entre as variáveis independentes}

\begin{tabular}{|c|c|c|c|c|c|c|c|c|c|c|c|c|c|c|}
\hline & & (1) & (2) & (3) & (4) & (5) & (6) & (7) & (8) & (9) & (10) & (11) & (12) & (13) \\
\hline$(1)$ & VM & 1,00 & & & & & & & & & & & & \\
\hline$(2)$ & QdT & 0,54 & 1,00 & & & & & & & & & & & \\
\hline (3) & EVA & 0,05 & 0,11 & 1,00 & & & & & & & & & & \\
\hline$(4)$ & $\mathrm{ROA}$ & 0,24 & 0,35 & 0,28 & 1,00 & & & & & & & & & \\
\hline (5) & ROE & 0,17 & 0,19 & 0,40 & 0,53 & 1,00 & & & & & & & & \\
\hline$(6)$ & MLiq & 0,07 & 0,22 & 0,00 & 0,04 & 0,00 & 1,00 & & & & & & & \\
\hline$(7)$ & LC & 0,06 & 0,25 & 0,09 & 0,14 & 0,08 & 0,44 & 1,00 & & & & & & \\
\hline$(8)$ & LG & $-0,27$ & 0,04 & 0,06 & 0,11 & 0,05 & $-0,02$ & 0,48 & 1,00 & & & & & \\
\hline (9) & LN-A & 0,86 & 0,02 & $-0,01$ & 0,06 & 0,08 & $-0,05$ & $-0,08$ & $-0,34$ & 1,00 & & & & \\
\hline (10) & Ded. F. & 0,31 & 0,21 & 0,03 & 0,11 & 0,07 & 0,05 & $-0,02$ & $-0,10$ & 0,23 & 1,00 & & & \\
\hline (11) & GIM & 0,22 & $-0,12$ & $-0,06$ & $-0,13$ & $-0,03$ & $-0,06$ & $-0,44$ & $-0,61$ & 0,33 & 0,05 & 1,00 & & \\
\hline (12) & Ind. & $-0,07$ & 0,02 & $-0,09$ & $-0,01$ & $-0,07$ & 0,06 & 0,08 & $-0,12$ & $-0,09$ & 0,08 & 0,01 & 1,00 & \\
\hline (13) & Op.C & 0,48 & 0,84 & 0,05 & 0,34 & 0,11 & 0,05 & 0,02 & $-0,03$ & 0,05 & 0,16 & $-0,13$ & 0,02 & 1,00 \\
\hline
\end{tabular}


As variáveis Log do Ativo e valor de mercado foram excluídas do modelo pelo processo de stepwise (Hair et al., 2009), e as variáveis Q de Tobin e "oportunidade de crescimento" apresentaram critério de Tolerance de 0,295 e 0,288, respectivamente, pois de acordo com Corrar, Paulo e Dias Filho (2007), valores entre 0,10 e 1 estão em um padrão de multicolinearidade aceitável.

Pela análise da discriminante, observa-se que a correlação canônica apresentou valor baixo 0,658 , entretanto, ainda significativo para verificar a existência de influência da estrutura de capital no desempenho da firma, lembrando-se que a correlação canônica é utilizada para analisar o ajuste das variáveis extraídas pelo método. Dessa forma, esse valor elevado ao quadrado trabalha de forma similar ao coeficiente de determinação e, no caso analisado, significa que 43,3\% das variâncias das variáveis são explicadas pelo modelo discriminante, o que demonstra, segundo Corrar et al. (2007), que a técnica não é perfeita, mas apresenta um determinado grau de confiabilidade.

Com a análise discriminante, avaliaram-se também quais variáveis melhor discriminam os grupos em questão (muito alavancado e pouco alavancado). Observa-se que apenas LG, GIM, Q de Tobin, e a Op.C, foram significativas a 1\% para discriminar os grupos após o processo stepwise. Esse resultado pode ser mais bem visualizado na Tabela 5 .

Tabela 5

Variáveis significativas para o modelo

\begin{tabular}{|c|c|c|c|c|c|c|c|c|c|}
\hline \multirow{3}{*}{ Etapa } & \multirow{3}{*}{ Inseridas } & \multicolumn{8}{|c|}{ Lambda de Wilks } \\
\hline & & \multirow{2}{*}{ Estatística } & \multirow{2}{*}{ df1 } & \multirow{2}{*}{ df2 } & \multirow{2}{*}{ df3 } & \multicolumn{4}{|c|}{ F exato } \\
\hline & & & & & & Estatística & df1 & df2 & Sig. \\
\hline 1 & LG & 0,810 & 1 & 1 & 161,00 & 37,78 & 1 & 161,00 & 0,00 \\
\hline 2 & GIM & 0,694 & 2 & 1 & 161,00 & 35,33 & 2 & 160,00 & 0,00 \\
\hline 3 & Q de Tobin & 0,617 & 3 & 1 & 161,00 & 32,92 & 3 & 159,00 & 0,00 \\
\hline 4 & Op.C & 0,563 & 4 & 1 & 161,00 & 30,65 & 4 & 158,00 & 0,00 \\
\hline
\end{tabular}

Fonte: dados da pesquisa.

Segundo Corrar et al. (2007), a importância de cada variável dentro da função discriminante pode ser compreendida pelo método de análise dos coeficientes padronizados da função canônica. Dessa forma, as variáveis mais relevantes para o estudo, em ordem de importância e desconsiderando os sinais positivos e negativos, foram: o Q de Tobin $(1,201)$, a "oportunidade de crescimento" $(-0,867)$, a liquidez geral $(0,836)$; e o "grau de imobilização" $(0,616)$.

Outro método que permite uma interpretação mais aproximada da importância dos valores reais, conforme Corrar et al. (2007), é a tabela dos coeficientes não padronizados da função discriminante canônica (Tabela 6). A priori, observa-se que o grau de imobilização (GIM), contrapõe a aceitação tanto da STT como para a POT, sendo que ambas relacionam positivamente a tangibilidade dos ativos e o nível do endividamento. Os resultados indicam que o grau de imobilização está diretamente relacionado com o Grupo 1, ou seja, quanto maior o nível de tangibilidade dos ativos, menor o endividamento da firma.

Tabela 6

Coeficientes de funções discriminantes canônicas não padronizados

\begin{tabular}{cc}
\hline Variáveis & Função 1 \\
\hline Q de Tobin & 1,154 \\
\hline LG & 1,411 \\
\hline GIM & 1,271 \\
\hline Oport. Cresc. & $-1,777$ \\
\hline (Constante) & $-3,796$ \\
\hline
\end{tabular}

Fonte: dados da pesquisa. 
Entre as variáveis de desempenho da firma, somente o Q de Tobin e a liquidez geral apresentaram resultados significativos para a função discriminante, contribuindo para o fato que, quanto maior o valor dessas variáveis, maior será a possibilidade de a empresa estar presente no grupo de menor grau de endividamento. Esta relação negativa entre endividamento e alavancagem tem o respaldo na POT, conforme afirmam Bressan et al. (2008), Terra (2002) e Rajan e Zingales (1995).

Nesta mesma perspectiva, os resultados demonstraram um coeficiente negativo na função discriminante para a variável oportunidade de crescimento, contribuindo para que quanto maior for essa variável, maior será a probabilidade de a firma estar inserida no Grupo 2, que possui maior nível de endividamento. Esta correlação positiva vai ao encontro da POT, no sentido de que as oportunidades de crescimento estão positivamente relacionadas com o endividamento da firma, sendo que o crescimento elevado não disponibiliza subsídios suficientes para elas se financiarem com recursos internos. Isso irá obrigá-las a possuírem uma maior alavancagem, conforme apontam Gomes (1999) e Terra (2002).

Para findar a discussão, verifica-se o grau de acerto da função discriminante ao tentar classificar os grupos. Como pode ser visto na Tabela 7 , o percentual de acerto foi de $86,1 \%$ dos casos originais, o que representa um bom percentual.

Tabela 7

Resultados da classificação *

\begin{tabular}{|c|c|c|c|c|c|}
\hline & & \multirow{3}{*}{ Grupo_EndivT } & \multirow{2}{*}{\multicolumn{2}{|c|}{ Associação ao grupo previsto }} & \\
\hline & & & & & \multirow{2}{*}{ Total } \\
\hline & & & 1 & 2 & \\
\hline \multirow{4}{*}{ Amostra Original } & \multirow{2}{*}{ Contagem } & 1 & 47 & 15 & 86 \\
\hline & & 2 & 8 & 93 & 101 \\
\hline & \multirow{2}{*}{$\%$} & 1 & 75,8 & 24,2 & 100,0 \\
\hline & & 2 & 7,9 & 92,1 & 100,0 \\
\hline \multirow{4}{*}{ Amostra para Teste } & \multirow{2}{*}{ Contagem } & 1 & 19 & 5 & 24 \\
\hline & & 2 & 5 & 46 & 51 \\
\hline & \multirow{2}{*}{$\%$} & 1 & 79,2 & 20,8 & 100,0 \\
\hline & & 2 & 9,8 & 90,2 & 100,0 \\
\hline
\end{tabular}

*.: 86,1\% de casos originais agrupados corretamente classificados.

Fonte: dados da pesquisa.

Os resultados da amostra original demonstram que 15 empresas que possuíam baixos níveis de endividamento foram classificadas como sendo empresas altamente endividadas. No que concerne às empresas com alto nível de endividamento, 8 foram consideradas erroneamente como empresas de baixo nível de endividamento. Já em relação à amostra teste, 5 empresas com baixo nível de endividamento foram classificadas como altamente endividadas, e 5 empresas altamente endividadas foram classificadas com baixo nível de endividamento.

\section{Considerações Finais}

Baseado em teorias relevantes acerca da estrutura de capital, foram testados diversos indicadores. Entre esses, observou-se que apenas a liquidez geral, grau de imobilização, Q de Tobin e a oportunidade de crescimento foram significativos a 1\% para discriminar os grupos após o processo stepwise. Destas, pode-se destacar que o grau de imobilização foi contrário ao que pressupõe as duas correntes teóricas (STT e POT).

A variável de controle, "oportunidade de crescimento", foi significativa, apontando para uma correlação positiva entre endividamento e desempenho da firma, o que confirma, para a presente amostra, 
uma adequação à teoria pecking order. Nesse contexto, as variáveis de desempenho $\mathrm{Q}$ de Tobin e liquidez geral apresentaram significância estatística ao demonstrar uma correlação negativa entre endividamento e desempenho, dando destaque a teoria pecking order e aos trabalhos de Modigliani e Miller.

A contribuição teórica deste estudo é trazer para a pauta de discussão no campo da teoria Financeira o debate sobre a relevância da estrutura de capital e suas diferentes abordagens. O aporte empírico baseia-se na aplicabilidade das teorias referentes à estrutura de capital no contexto das empresas brasileiras listadas na BM\&FBOVESPA, e no aporte para os gestores financiarem seus investimentos.

Uma das limitações do trabalho está relacionada com a não observância dos dados em um período significativo de tempo, tendo em vista a utilização do corte transversal para a análise. Outro fator limitador do trabalho é não considerar os aspectos qualitativos que podem interferir na tomada de decisão acerca da melhor estrutura de capital. Como sugestão de agenda para estudos futuros, aconselha-se uma pesquisa mais detalhada que considere os aspectos qualitativos e quantitativos do processo, ou mesmo um trabalho focado em determinado setor industrial.

Por fim, cabe salientar que não se rejeitou a hipótese nula de que a estrutura de capital não esteja diretamente relacionada com o desempenho das firmas brasileiras listadas na BM\&FBOVESPA. Neste ínterim, os resultados apontam para a consolidação das teorias financeiras expostas por Modigliani e Miller $(1958,1963)$ em oposição à corrente tradicionalista iniciada nos estudos de Durand (1952).

\section{Referências}

Abhijit, D. (2013). Lemon Problem and Pecking Order theory: An Investigation on Indian Corporate sector. Vilakshan: The XIMB Journal of Management, 10(2), pp. 73-82.

Albanez, T. (2012). Efeitos do market timing sobre a estrutura de capital de companhias abertas brasileiras. Tese de doutorado, Universidade de São Paulo, São Paulo, SP, Brasil.

Almeida, M. A. (2014). Estrutura de capital e divulgação voluntária de informações de responsabilidade social corporativa das empresas brasileiras. Tese de doutorado, Universidade Federal de Pernambuco, Recife, PE, Brasil.

Andersen, T. J. (2005). Risk management, capital structure, and performance: a real options perspective. Global Business \& Economics Anthology, 24(2), pp. 1-19.

Angonese, R., dos Santos, P. S. A., \& Lavarda, C. E. F. (2011). Valor Econômico Agregado (VEA) e estrutura de capital em empresas do IBRX 100. ConTexto, 11(20), pp. 7-17.

Assaf Neto, A. (2009). Finanças corporativas e valor (4a ed.). São Paulo: Atlas.

Atiyet, B. A. (2012). The Pecking Order Theory and the Static Trade Off Theory: Comparison of the Alternative Explanatory Power in French Firms. Journal of Business Studies Quarterly, 4(1), pp. 1-14.

Baker, M., \& Wurgler, J. (2002). Market timing and capital structure. Journal of Finance, 57(1), pp. 1-32. doi: 10.1111/1540-6261.00414

Bartholdy, J., Mateus, C., \& Olson, D. (2015). Do Portuguese private firms follow pecking order financing? European Journal of Finance, 21(10/11), pp. 848-866. doi: 10.1080/1351847X.2012.706815

Bastos, D. D.; Nakamura, W. T. (2009). Determinantes da estrutura de capital das companhias abertas no Brasil, México e Chile no período 2001-2006. Revista Contabilidade \& Finanças-USP, 20(50), pp. 75-94.

Bezerra, F. A., \& Corrar, L. J. (2006). Utilização da análise fatorial na identificação dos principais indicadores para avaliação do desempenho financeiro: uma aplicação nas empresas de seguros. Revista de Contabilidade e Finanças-USP, (42), pp. 50-62.

Bonacim, C. A. G., Ambrozini, M. A., \& Nagano, M. S. (2006). Estudo de causalidade entre alavancagem 
financeira e eficiência operacional das empresas brasileiras de capital aberto no período de 1996 a 2004-2006. FIPECAFI Pesquisa Contábil e Desenvolvimento Econômico Social, pp. 1-16.

Braga, R., Nossa, V., \& Marques, J. A. V. D. C. (2004). Uma proposta para a análise integrada da liquidez e rentabilidade das empresas. Revista Contabilidade \& Finanças, 15(SPE), pp. 51-64.

Bressan, V. G. F., Bressan, A. A., Lima, J. E. D., \& Braga, M. J. (2008). Análise da alavancagem das empresas de capital aberto do agronegócio brasileiro: uma abordagem usando Logit Multinomial. Revista de Economia e Agronegócio (REA), 6(1), pp. 51-80.

Brusov, P., Filatova, T., Orehova, N., \& Brusova, N. (2011). Weighted average cost of capital in the theory of Modigliani-Miller, modified for a finite lifetime company. Applied Financial Economics, 21(11), pp. 815-824. doi: 10.1080/09603107.2010.537635

Canarella, G., Nourayi, M., \& Sullivan, M. J. (2014). An alternative test of the trade-off theory of capital structure. Contemporary Economics, 8(4), pp. 365-386. doi: 10.5709/ce.1897-9254.151

Casey, C. (2012). Capital Structure Analysis and the Trade-Off Theory - Theoretical Considerations and Empirical Findings from the German DAX 30 Companies. Betriebswirtschaftliche Forschung und Praxis, 64(2), pp. 163-189.

Chen, D. H., Chen, C. D., Chen, J. G., \& Huang, Y. F. (2013). Panel data analyses of the pecking order theory and the market timing theory of capital structure in Taiwan. International Review of Economics \& Finance, 27, pp. 1-13. doi: 10.1016/j.iref.2012.09.011

Corrar, L. J., Paulo, E., \& Dias Filho, J. M. (2007). Análise multivariada: para os cursos de administração, ciências contábeis e economia. São Paulo: Atlas.

Correa, C. A., Cruz Basso, L. F., \& Nakamura, W. T. (2013). The capital structure of largest brazilian firms: an empirical analysis of the pecking order and trade-off theories, using panel data. RAM-Revista de Administracao Mackenzie, 14(4), pp. 106-133.

Cruz, A. P. C. D., Mendes, R. D. C., Espejo, M. M. D. S. B., \& Dameda, A. D. N. (2008). A estrutura de capital de empresas do sul brasileiro como um condicionante à rentabilidade - Um estudo empírico à luz de teorias financeiras. Sinergia, 12(2), pp. 9-20.

Daher, C. E. (2004). Testes empíricos de teorias alternativas sobre a determinação da estrutura de capital das empresas brasileiras. Dissertação de Mestrado, Universidade Federal de Brasília, Brasília, DF, Brasil.

Damodaran, A. (2004). Finanças corporativas: teoria e prática (2a ed.). Porto Alegre: Bookman.

Donaldson, G. (1961). Corporate debt capacity: A study of corporate debt policy and the determination of corporate debt capacity. Boston: Harvard Graduate School of Business Administration.

Durand, D. (1952). Costs of debt and equity funds for business: trends and problems of measurement. Paper presented at the Conference on research in business finance. NBER. pp. 215-262.

Durand, D. (1959). The Cost of Capital, Corporation Finance, and the Theory of Investment: Comment. American Economic Review, 49(4), pp. 639-655.

Ferreira, L. D. S., \& Brasil, H. (1997). Estrutura de capital: um teste preliminar da "pecking order hypothesis". Anais do Encontro Nacional da Associação Nacional de Pós-Graduação e Pesquisa em Administração, Rio de Janeiro, RJ, Brasil, 21.

Field, A. (2009). Descobrindo a estatistica usando o SPSS (2 a ed.). Bookman.

Forte, D. (2007). Estudo sobre a estrutura de capital das empresas brasileiras no período pós-Plano Real (1995-2005). Tese de Doutorado, Universidade Presbiteriana Mackenzie, São Paulo, SP, Brasil.

Futema, M. S., Basso, L. F. C., \& Kayo, E. K. (2009). Estrutura de capital, dividendos e juros sobre o capital 
próprio: testes no Brasil. Revista Contabilidade \& Finanças. 20(49), pp. 44-62.

Ghazouani, T. (2013). The Capital Structure Through the Trade-Off Theory: Evidence from Tunisian Firm. International Journal of Economics and Financial Issues, 3(3), pp. 625-636.

Gomes, G. L. (1999). Determinantes da estrutura de capitais das empresas brasileiras com ações negociadas em bolsas de valores. Tese de Doutorado, Universidade Federal do Rio de Janeiro, RJ, Brasil.

Groppelli, A. A., \& Nikbakht, E. (2002). Administração financeira (2a ed.). São Paulo: Saraiva.

Grzebieluckasa, C., Marconb, R., Albertonc, A., \& Bandeira-de-Mellod, R. (2008). A estrutura de capital e a performance das firmas: uma análise empírica em companhias abertas no Brasil. Revista Brasileira de Estratégia, 1(1), pp. 73-88.

Hair, J. F., Black, W. C., Babin, B. J., Anderson, R. E., \& Tatham, R. L. (2009). Análise multivariada de dados. Bookman.

Hovakimian, A., Kayhan, A., \& Titman, S. (2012). Are Corporate Default Probabilities Consistent with the Static Trade-off Theory? Review of Financial Studies, 25(2), pp. 315-340. doi: 10.1093/rfs/hhr101

Islam, S. Z., \& Khandaker, S. (2015). Firm leverage decisions: Does industry matter? North American Journal of Economics \& Finance, 31, 94-107. doi: 10.1016/j.najef.2014.10.005

Jensen, M. C., \& Meckling, W. H. (1976). Theory of the firm: Managerial behavior, agency costs and ownership structure. Journal of Financial Economics, 3(4), pp. 305-360. doi: 10.1016/0304-405X(76)90026-X

Mangafić, J., \& Martinović, D. (2015). The firm-specific determinants of the target capital structure: Evidence from Bosnia and Herzegovina panel data. Mediterranean Journal of Social Sciences, 6(2S5), pp. 188-198. doi: 10.5901/mjss.2015.v6n2s5p188

Martins, A. I., \& Famá, R. (2012). O que revelam os estudos realizados no Brasil sobre política de dividendos? Rae-Revista De Administracao De Empresas, 52(1), pp. 24-39.

Matarazzo, D. C. (2007). Analise financeira de balanços: abordagem básica e gerencial (6a ed.). São Paulo: Atlas.

Modigliani, F., \& Miller, H. M. (1958). The cost of capital, corporation finance and the theory of investment. The American Economic Review, 48(3), pp. 261-297. doi: 10.2307/1809766

Modigliani, F., \& Miller, H. M. (1959). The cost of capital, corporation finance, and the theory of investment: reply. The American Economic Review, 55(3), pp. 524-527. doi: 10.2307/1814566

Modigliani, F., \& Miller, H. M. (1963). Corporate Income Taxes and the Cost of Capital: A Correction. The American Economic Review, 53(3), pp. 433-443. doi: 10.2307/1809167

Mukherjee, S., \& Mahakud, J. (2012). Are Trade-off and Pecking Order Theories of Capital Structure Mutually Exclusive? Journal of Management Research (09725814), 12(1), pp. 41-55.

Myers, S. C. (1984). The capital structure puzzle. Journal of Finance, 39(3), pp. 575-592. doi: 10.2307/2327916

Myers, S. C. (2001). Capital structure. Journal of Economic Perspectives, 15(2), pp. 81-102. doi: 10.1257/ jep.15.2.81

Myers, S. C., \& Majluf, N. S. (1984). Corporate financing and investment decisions when firms have information that investors do not have. Journal of Financial Economics, 13(2), pp. 187-221. doi: 10.1016/0304-405X(84)90023-0

Nisiyama, E. K., \& Nakamura, W. T. (2014). Pesquisas Internacionais Recentes Em Estrutura De Capital. Anais do Seminário em Administração, SEMEAD, São Paulo, SP, Brasil. 17.

Oliveira, L., \& Antonialli, L. M. (2004). Uso da estrutura de capital por empresas agroindustriais. Organizações Rurais \& Agroindustriais, 6(2), pp. 134-148.

Padoveze, C. L. (2003). Controladoria estratégica e operacional: conceitos, estrutura, aplicação. São Paulo: 
Pioneira Thomson Learning.

Perobelli, F. F. C., \& Famá, R. (2002). Determinantes da estrutura de capital: aplicação a empresas de capital aberto brasileiras. Revista de Administração da Universidade de São Paulo, 37(3), pp. 33-46.

Pessanha, G. R. G., Calegario, C. L. L., Safadi, T., \& De Azara, L. N. (2012). Impactos das estratégias de fusão e aquisição na rentabilidade dos bancos adquirentes: uma aplicação dos modelos de intervenção no setor bancário brasileiro. RAM, REV. ADM. Mackenzie, 13(5), pp. 101-134.

Pirtea, M., Nicolescu, C., \& Boţoc, C. (2014). Do romanian companies follow pecking order financing? Economic Computation \& Economic Cybernetics Studies \& Research, 48(1), pp. 1-15.

Pohlmann, M. C., Aguiar, A. B. D., Bertolucci, A., \& Martins, E. (2004). Impacto da especificidade de ativos nos custos de transação, na estrutura de capital e no valor da empresa. Revista Contabilidade \& Finanças, 15(SPE), pp. 24-40.

Rajan, R. G. (2012). Presidential Address: The Corporation in Finance (Vol. 67, pp. 1173-1217): Wiley-Blackwell. doi: 10.1111/j.1540-6261.2012.01745.x

Rajan, R. G., \& Zingales, L. (1995). What Do We Know about Capital Structure? Some Evidence from International Data. Journal of Finance, 50(5), pp. 1421-1460. doi: 10.1111/j.1540-6261.1995.tb05184.x

Ross, S. A. (1977). The determination of financial structure: the incentive-signalling approach. The bell journal of economics, pp. 23-40. doi: 10.2307/3003485

Ross, S. A., Westerfield, R. W., \& Jaffe, J. F. (2007). Administração Financeira (2ª ed.). São Paulo: Atlas.

Serrasqueiro, Z., \& Caetano, A. (2015). Trade-Off Theory versus Pecking Order Theory: capital structure decisions in a peripheral region of Portugal. Journal of Business Economics and Management, 16(2), pp. 445-466. doi: 10.3846/16111699.2012.744344

Silva Junior, F. P. D. (2012). A estrutura do capital das PME'S e das grandes empresas: uma análise comparativa. Dissertação de Mestrado, Faculdade de Economia da Universidade de Coimbra. Portugal. Recuperado de https://eg.sib.uc.pt/handle/10316/20000

Silva, S. S. F. P. J. (2013) A estrutura de financiamento das empresas não financeiras do PSI 20. Dissertações de mestrado, Escola Superior de Ciências Empresariais, IPS - Instituto Politécnico de Setúbal, Portugal. Recuperado de http://hdl.handle.net/10400.26/6197

Sirihal, A. B., \& Melo, A. A. (1999). Estrutura de capital: benefícios e contra-benefícios fiscais do endividamento. Anais do Encontro Nacional da Associação Nacional de Pós-Graduação e Pesquisa em Administração, Foz do Iguaçu, PR, Brasil, 23.

Terra, P. R. S. (2002). An empirical investigation on the determinants of capital structure in Latin America. Anais do Encontro Nacional da Associação Nacional de Pós-Graduação e Pesquisa em Administração, Salvador, BA, Brasil, 26.

Titman, S., \& Wessels, R. (1988). The determinants of capital structure choice. The journal of Finance, 43(1), pp. 1-19. doi: 10.1111/j.1540-6261.1988.tb02585.x

Virgillito, S. B., \& Famá, R. (2008). Estatística multivariada na construção de modelos para análise do risco de crédito e previsão de insolvência de empresas. Revista Integração, 53(13), pp. 105-118.

Zou, H., \& Xiao, J. Z. (2006). The financing behaviour of listed Chinese firms. British Accounting Review, 38(3), pp. 239-258. doi: 10.1016/j.bar.2006.04.008 